\title{
CONSTRUÇÃO DE IDENTIDADES NA APRENDIZAGEM DE LÍNGUA INGLESA: INTERAÇÕES COMUNICATIVAS, AUTOESTIMA E INVESTIMENTO ${ }^{1}$
}

\author{
Aline Cajé BERNARDO \\ Doutorado em Educação - Universidade Federal de Sergipe
}

RESUMO: As relações entre linguagem e identidade são de grande importância no processo de ensino e aprendizagem de línguas. Aprender uma língua estrangeira possui uma dimensão identitária, pois envolve, entre outras coisas, tornar-se um outro (REVUZ, 1998). Esse despertar para uma outra língua pode funcionar como um reforço narcísico sobre aquele que aprende. Este artigo baseia-se em depoimentos de alunos do ensino fundamental, obtidos em uma pesquisa de mestrado cujo objetivo foi compreender os sentidos atribuídos à aprendizagem de inglês, com base na teoria da Relação com o Saber (CHARLOT, 2000, 2005). A pesquisa, de cunho qualitativo, foi realizada com 115 alunos de duas escolas, sendo uma pública e outra privada. Para tanto, foram aplicados questionários semiestruturados e realizadas 15 entrevistas. Este artigo, com base nesses dados, analisa de que forma as interações comunicativas desses estudantes com pessoas de outras nacionalidades podem contribuir para a ressignificação das suas identidades enquanto aprendizes de língua inglesa. As análises foram pautadas em Norton (1997), no tocante às noções de identidade e investimento; em Rajagopalan (2003), nos aspectos de identidade e autoestima; e em Charlot (2000) e Develay (1996), no que concerne às noções de reforço narcísico e sentido. Os resultados mostraram que as experiências comunicativas em outra língua afetaram sua relação consigo mesmo e com o idioma, mobilizando-os a investirem-se mais na sua aprendizagem.

PALAVRAS-CHAVE: língua inglesa; identidade; investimento.

ABSTRACT: The relationship between language and identity is very important in language teaching and learning. Learning a new language includes an identity dimension because it involves, among other things, to become another person (REVUZ, 1998). This arouse to another language may cause in learners a narcissistic reinforcement. This paper is based on the data gathered among elementary school students, during a Master degree research, grounded on the Relationship to Knowledge theory (CHARLOT, 2000; 2005), whose objective was to comprehend the senses the pupils attribute to the English language learning. This qualitative research was carried out with 115 pupils from a public school and a private one, through semistructured questionnaires and 15 interviews. This paper, based on the data mentioned, analyses how the communicative interactions of those pupils with foreign people could contribute to reformulating their identitites as English language learners. The analysis was grounded on Norton (1997) as for the identity and investment concepts; Rajagopalan (2003), concerning identity and self-esteem; Charlot (2000) and Develay (1996) as for the concepts of narcissistic reinforcement and sense. The results showed that the communicative experiences affected their relationship with the English language, mobilising them to invest themselves in the learning of this language.

KEYWORDS: English language; identity; investment.

\footnotetext{
${ }^{1}$ Uma versão similar a este artigo, derivado de uma pesquisa de Mestrado, foi publicada na Revista Cadernos do Tempo Presente n. 23 (2016), disponível em http://www.seer.ufs.br/index.php/tempo/issue/view/477/showToc
} 


\section{CONSTRUÇÃO DE IDENTIDADES NA APRENDIZAGEM DE LÍNGUA INGLESA: INTERAÇÕES COMUNICATIVAS, AUTOESTIMA E INVESTIMENTO}

\section{Introdução}

As relações entre linguagem e identidade são de extrema importância para o ensino e aprendizagem de línguas. Muitas vezes, não tem sido dado o merecido destaque a esse aspecto, o que tem resultado em práticas escolares, nesse âmbito, pouco significativas, tanto para os alunos quanto para os professores. Isso pode refletir a compreensão que os docentes têm da língua como sistema de signos e não como uma prática social através da qual os aprendizes do idioma conseguem fazer uso daquilo que aprendem, ressignificando o mundo em que vivem e a si mesmos.

Este artigo tem o objetivo de analisar de que forma as interações comunicativas de alunos do Ensino Fundamental com pessoas de outras nacionalidades contribuíram para a ressignificação das suas identidades enquanto aprendizes de língua inglesa, resultando numa nova relação com a aprendizagem do idioma.

Os dados apresentados são derivados de minha pesquisa de mestrado, com base na teoria da Relação com o Saber, sobre os sentidos de se aprender inglês na escola, no Ensino Fundamental, para a qual foram aplicados questionários com 115 estudantes e realizadas entrevistas com 15 deles. Para este artigo, priorizei uma das perguntas do questionário: "Você já se comunicou com algum estrangeiro em inglês? Se sua resposta for sim, conte como aconteceu e como você se sentiu?". Com base nas respostas, que foram inicialmente analisadas principalmente segundo o pensamento de Charlot (2000, 2005), Develay (1996) e Almeida Filho (2005), este artigo busca atualizar a análise sob a luz dos conceitos de Norton (1997, 2011), Hall (2005), Rajagopalan (2003), dentre outras leituras posteriores à dissertação.

A próxima seção explicita os conceitos supramencionados, buscando algumas convergências entre eles e os autores utilizados na dissertação. Em sequência, são expostas as noções e os conceitos da teoria da Relação com o Saber, os depoimentos dos alunos pesquisados, bem como a análise dos dados.

\section{Identidade e aprendizagem de línguas estrangeiras no mundo globalizado}

Muitos estudiosos do conhecimento em língua estrangeira apontam para a importância de se abordar as questões de identidade no ensino de línguas. Revuz (1998) afirma que aprender uma língua é tornar-se um outro; Rajagopalan (2003, p. 69) diz que "quem aprende uma língua nova está se redefinindo como pessoa", por exemplo. No entanto, é preciso ter em mente que a identidade não é algo fixo ou essencialista (como constitutiva da essência de 
alguém), mas está sempre se reconstruindo e se redefinindo, especialmente com o processo atual de globalização.

Neste artigo, corroboramos o pensamento de Hall (2005) de que a identidade não é estável, fixa e permanente, mas é definida historicamente. Isso está em consonância com a declaração de Rajagopalan $(2003$, p. 69) quando afirma que "as identidades estão cada vez mais sendo percebidas como precárias e mutáveis, suscetíveis a renegociação constante". Nesse sentido, o sujeito pode assumir várias identidades em diferentes momentos. Isso deveria ser de especial interesse nos tempos atuais, a era da globalização, em que existem novas relações com o tempo e o espaço, em que o mundo tem suas fronteiras encurtadas ou deslocadas (AUGÉ, 2010).

No que concerne à globalização, Charlot (2007, p. 134, grifo nosso) acrescenta:

[...] a globalização é, antes de tudo, um processo socioeconômico. Todavia, ela traz também conseqüências culturais, através do encontro entre culturas e do aparecimento e espalhamento de novas formas de expressão. Cabe destacar a miscigenação entre povos devido aos fenômenos de migração acrescida, a divulgação mundial de informações e imagens pela mídia audiovisual e a Internet, a ampla difusão de produtos culturais (filmes, novelas, séries televisuais, músicas), a generalização do uso do inglês ou de uma língua internacional baseada nele, em detrimento de outras línguas. As consequiências culturais e até sócio-cognitivas desses fenômenos ainda são difíceis de serem avaliadas, mas não há dúvida de que constituem novos desafios a serem enfrentados pela escola.

Em um mundo assim, de acordo com Suárez-Orozco (2003), estão em vantagem social aqueles que conseguem se mover fluidamente entre línguas e culturas, aqueles que possuem competências bilíngues e biculturais. Esta autora se reporta ao contexto de jovens imigrantes que chegam aos Estados Unidos e se veem confrontados com os dilemas de adaptação à nova cultura e com a necessidade de formulação de novas identidades, muitas vezes, tendo que deixar para trás sua pátria, seus pais, parentes e amigos.

O contexto de que trata o presente artigo é diferente: refere-se a jovens de um país não anglófono que aprendem a língua inglesa como língua estrangeira na escola regular. Em sua maioria, são oriundos das classes populares e nunca viajaram para os Estados Unidos, nem para outro país que tenha como língua oficial o inglês, mas que se veem confrontados com o desejo ou a imposição de estudar esse idioma, uma vez que ele predomina no currículo escolar. Mesmo assim, as questões atinentes à formação de identidades são relevantes. Apesar do fato de esses estudantes não estarem se deslocando fisicamente como os jovens pesquisados por Suaréz-Orozco (2003), com eles ocorre o que Kumaravadivelu (2007, p. 174) constatou: "se os aprendentes de uma língua estrangeira não vão ao mundo, o mundo vem até eles" ${ }^{2}$.

2 [...] even if the L2 learners do not go to the world, the world will come to them. (As traduções das citações em língua estrangeira são de minha autoria). 
Ainda no que tange às questões de identidade, compartilhamos também do pensamento de Norton (1997, p. 410) que a considera como algo que varia de acordo com as mudanças sociais e com as relações econômicas. Esta autora afirma que as diferenças entre identidade social e identidade cultural são bastante fluidas, e que as pesquisas recentes estão voltadas mais para os pontos de convergência entre esses constructos do que para as suas diferenças. Nesse sentido, segundo esta autora, a identidade é construída socioculturalmente e refere-se à maneira como as pessoas compreendem sua relação com o mundo.

Além disso, em suas pesquisas sobre identidade, Norton utiliza o termo "investimento" ao invés de motivação, argumentando que este último termo não dá conta das relações desiguais de poder existentes entre os aprendizes de uma língua e seus falantes:

O constructo investimento, inspirado pelo trabalho de Bourdieu (1991), assinala a relação, construída socio-historicamente, dos aprendizes da língua-alvo com o seu desejo frequente e ambivalente de aprender essa língua e de praticá-la. Se os aprendizes "investem" na língua-alvo, eles o fazem com a compreensão de que irão ampliar seus recursos simbólicos e materiais, que irão, por sua vez, aumentar o valor de seu capital cultural. (NORTON, 2011, p. 322) $)^{3}$

A autora afirma que a maioria das teorias percebe a motivação como um traço individual do sujeito, como um constructo psicológico, de modo que aqueles que fracassam na aprendizagem são vistos como não estando engajados no processo, ou seja, estão desmotivados. Segundo a autora, o "investimento", no entanto, apresenta uma perspectiva social e exprime melhor a relação do aprendiz com a língua-alvo, pois considera as implicações das relações de poder envolvidas neste processo e também as identidades daqueles que aprendem.

Outro autor que prefere não utilizar o termo motivação é Charlot (2001, p. 19), que afirma:

Não estou pensando em termos de motivação, em como vou fazer para motivar os alunos. Não é esse o problema. O problema para mim é o que posso fazer para que o aluno se mobilize. A mobilização é um movimento interno do aluno, é a dinâmica interna do aluno que, evidentemente, se articula com o problema do desejo.

À primeira vista, a perspectiva de Charlot quanto à mobilização parece permanecer no âmbito do constructo psicológico - apontado por Norton em referência à motivação -, pois nos

\footnotetext{
${ }^{3}$ The construct of investment, inspired by the work of Bourdieu (1991), signals the socially and historically constructed relationship of learners to the target language and their often ambivalent desire to learn and practise it. If learners 'invest' in the target language, they do so with the understanding that they will acquire a wider range of symbolic and material resources, which will in turn increase the value of the cultural capital.
} 
fala do movimento interno e do desejo do aluno. O próprio autor assume essa dimensão, ao afirmar que "nesse caminho, a sociologia encontra-se com a psicanálise", porém, a mobilização não permanece restrita à subjetividade, pois o autor acrescenta que, nesse encontro entre a sociologia e a psicanálise, a dinâmica do desejo é analisada tanto do ponto de vista pessoal quanto social, pois o sujeito interpreta o mundo e age sobre ele (CHARLOT, 2005, p. 19, 20).

Similarmente, é interessante observar que Norton, apesar de enfatizar a dimensão social, também aborda o problema do desejo, quando afirma que o investimento envolve uma relação com o desejo de aprender a língua-alvo e de colocá-la em prática. Isso nos traz de volta a Charlot (2005, p. 76) que utiliza o verbo "investir" tomado em relação com o desejo na questão da aprendizagem:

Uma aprendizagem só é possível se for imbuída do desejo (consciente ou inconsciente) e se houver um envolvimento daquele que aprende. Em outras palavras: só se pode ensinar a alguém que aceita aprender, ou seja, que aceita investir-se intelectualmente. $O$ professor não produz o saber no aluno, ele realiza alguma coisa (uma aula, a aplicação de um dispositivo de aprendizagem etc.) para que o próprio aluno faça o que é essencial, o trabalho intelectual (CHARLOT, 2005, p. 76, grifo nosso).

Embora haja nuances de diferenças no entendimento do termo investimento entre esses dois autores - Norton parece dar um sentido de recurso e Charlot o utliza na forma verbal, denotando ação -, há uma sintonia quanto à terminologia. Isso talvez se deva ao fato de que ambos tenham bebido da mesma fonte: a teoria sociológica de Pierre Bourdieu. Porém, na teoria da Relação com o Saber, Charlot inclui o pronome reflexivo "se". O sujeito investe não só os seus recursos como a si mesmo, pois esta teoria vai além das teorias da reprodução, visto que não considera exclusivamente a posição social do sujeito no processo educativo, mas também sua atividade e suas práticas, ou seja, o que o sujeito faz a partir de sua condição social.

No entanto, alguém só consegue investir-se em uma atividade intelectual quando encontra sentido nela. Conforme Michel Develay (1996, p. 91):

[...] o sentido se constrói, portanto, dentro da ação consciente do sujeito que se implica e que consegue olhar para esta implicação [...] Dar um sentido à sua ação, à sua vida, é dar a si mesmo um propósito, uma meta, um projeto pessoal e mais tarde profissional, é se construir uma identidade. ${ }^{4}$

\footnotetext{
${ }^{4}$ Le sens se construit ainsi dans l'action consciente du sujet qui s'implique et qui parvient à regarder cette implication [...] Donner un sens à son action, à sa vie, c'est donner un dessein, une fin, um projet personnel et plus tard professionnel, c'est se construire une identité.
} 
Em minha pesquisa de mestrado, busquei compreender que sentidos os alunos do ensino fundamental atribuíam à aprendizagem de inglês na escola, com base na teoria da Relação com o Saber. A pesquisa, de cunho qualitativo, foi realizada com 115 alunos de duas escolas, na cidade de Aracaju/SE, sendo uma escola pública, localizada em um bairro mais periférico e com alunos oriundos das classes populares, e outra privada, com uma clientela de classe média, em sua maioria. Para tanto, foram aplicados questionários semiestruturados e realizadas 15 entrevistas.

Nessa pesquisa, as ideias de Norton $(1997,2011)$ e Hall (2005), relacionadas à identidade, e as de Rajagopalan (2003), no tocante à autoestima, não foram consideradas, mas a leitura posterior desses textos durante uma disciplina do Doutorado contribuiu para que eu pudesse lançar um novo olhar sobre os dados, revisitando-os, até porque a teoria da Relação com o Saber apresenta uma dimensão identitária, que foi também considerada nas análises da dissertação. Em adição, minha inquietação inicial na problemática da pesquisa aproximava-se da afirmação de Rajagopalan (2003, p. 65): "No contexto de ensino de língua estrangeira, uma das perguntas quase nunca feitas pelos pesquisadores e professores é: 'Por que é que os alunos querem aprender uma língua estrangeira?"'. Estive indiretamente perguntando-lhes isso. Trago algumas de suas respostas e, em seguida, procuro relacioná-las às questões da identidade, investimento e autoestima.

\section{Relações com o aprender: Interações comunicativas e o reforço narcísico}

Conforme mencionado anteriormente, os dados que serão apresentados neste artigo, frutos de uma pesquisa de mestrado, foram analisados à luz da teoria da Relação como o Saber, que é uma "relação com o mundo, com o outro e consigo mesmo de um sujeito confrontado com a necessidade de aprender" (CHARLOT, 2000, p. 72). Para este autor (Idem, p. 81), "o conceito de relação com o saber implica o de desejo: não há relação com o saber senão a de um sujeito 'desejante"”.

Outra definição apresentada por este autor (Idem, p. 78) chama a atenção para o fato de que a relação com o saber é uma questão bem ampla:

A relação com o saber é o conjunto das relações que um sujeito estabelece com um objeto, um 'conteúdo de pensamento', uma atividade, uma relação interpessoal, um lugar, uma pessoa, uma situação, uma ocasião, uma obrigação, etc., relacionados de alguma forma ao aprender e ao saber conseqüientemente, é também relação com a linguagem, relação com o tempo, relação com a atividade no mundo e sobre o mundo, relação com os outros e consigo mesmo, como mais ou menos capaz de aprender tal coisa, em tal situação.

Visto que essa teoria está vinculada também a uma relação com a linguagem e com o aprender, buscou-se investigar que relações os alunos do Ensino Fundamental estabelecem 
com o aprender inglês como língua estrangeira no contexto escolar, tendo como questão central de pesquisa: Quais os sentidos atribuídos pelos alunos a essa aprendizagem. Isto porque "o sentido" é um dos elementos da teoria da Relação com o Saber. Segundo Charlot (2000. p. 64):

[...] tem sentido uma palavra, um enunciado, um acontecimento que possam ser postos em relação com outros em um sistema, ou em um conjunto; faz sentido para um indivíduo algo que lhe acontece e que tem relações com outras coisas de sua vida, coisas que ele já pensou, questões que ele já se propôs.

Por isso, buscou-se analisar que relações os alunos estabeleciam com a aprendizagem desse idioma no que se referia a si próprios, seus projetos, aos outros e ao mundo. Como resultados, verificou-se que os sentidos atribuídos a essa aprendizagem variaram em função do valor que cada aluno conferia ao idioma. Esse valor estava principalmente relacionado às questões de importância e/ou utilidade que a língua inglesa apresentava para a sua vida futura. Para eles, o inglês era importante para a utilização no futuro profissional, afinal, queriam um "futuro melhor". Isso nos remete a Rajagopalan (2003, p. 65) quando afirma que as pessoas tem se dedicado a aprender uma língua estrangeira "porque querem subir na vida", e que o domínio de línguas estrangeiras sempre foi visto como símbolo de intelectualidade e prestígio.

O fator "importância", atribuído ao inglês, presente na maioria de suas respostas, parecia reenviar a discursos de outros: familiares, professores ou mídia, pois as respostas não foram sustentadas por uma argumentação bem articulada, mas por expressões do tipo: "para ser alguém na vida", "posso precisar um dia" e "é a língua internacional".

A relação que eles estabeleciam com a maneira pela qual esse idioma estava sendo ensinado era de pouca credibilidade quanto a se ele pudesse realmente ser aprendido na escola. De acordo com seus depoimentos, nessa instituição, eram ensinados apenas rudimentos para cumprir a grade da disciplina e os aspectos gramaticais em que predominavam os verbos e especialmente o verbo to be. Para eles, era no curso de idiomas que o inglês era mais "puxado" ou aprofundado. Esses alunos gostariam que, no ensino de inglês na escola, fossem enfatizados os aspectos comunicativos da língua, principalmente a comunicação oral, pois, segundo declararam, saber inglês é principalmente saber falar e entender o idioma.

Revisitando agora aqueles dados, seleciono alguns depoimentos que enfatizaram a relação identitária com a aprendizagem da língua inglesa. Isto porque, além das dimensões epistêmica e social (relação com o mundo e com o outro), a teoria da Relação como o Saber compreende também uma dimensão identitária (consigo mesmo), que, embora seja a relação de um sujeito, não deixa de ser uma relação social. Tem esta dimensão porque "aprender faz sentido por referência à história do sujeito, às suas expectativas, às suas referências, à sua concepção da vida, às suas relações com os outros, à imagem que tem de si e a que quer dar de si aos outros" (CHARLOT, 2000, p. 72, 73). 
No intuito de compreender de que maneira e se o fato de conseguir efetivar uma comunicação com estrangeiros poderia afetar a relação dos alunos com o idioma e com eles próprios, perguntei se eles já haviam se engajado discursivamente com alguém de outro país de maneira mais vívida, para além dos textos e das leituras, e como foi essa experiência. Seus relatos revelaram:

Sim, numa loja de uma rede americana de roupas na Argentina, para pedir algumas peças de roupa e quase não consegui falar, pois tive medo de falar errado. (Aluno da escola particular $/ 9^{\circ}$ ano)

Sim, várias vezes. Em viagens internacionais, em aeroportos e lanchonetes, parques etc... Me senti bem, por estar me comunicando com outra pessoa, que não conheço, em outra língua. (Aluno da escola particular $/ 9^{\circ}$ ano)

Sim, quando fui a Disney. Não sabia falar muito porque tinha 10 anos, mas aprendi muito com eles. (Aluno da escola particular $/ 9^{\circ}$ ano)

Sim, ele (o estrangeiro) morava no meu prédio, eu e minhas amigas estávamos descendo com ele no elevador, começamos a conversar. Eu achei estranho. (Aluna da escola particular $/ 9^{\circ}$ ano)

Sim. Eu estava em um cruzeiro com meus pais e tinha uma menina da minha idade conversando comigo em inglês. Eu me senti orgulhosa. (Aluna da escola particular $/ 6^{\circ}$ ano)

Tais depoimentos apresentam frases na primeira pessoa do singular que evidenciam a imagem que os alunos e alunas tinham de si. Ao afirmarem: "tive medo de falar"; "me senti bem"; "eu achei estranho"; "eu estava calma" e "eu me senti orgulhosa", eles mostram a imagem que tinham de si e, em alguns casos, a que queriam dar a outros, no receio de cometerem equívocos ao falar.

No aspecto do medo de falar para não errar, podemos chamar a atenção para as relações entre linguagem e autoestima mencionadas por Rajagopalan (2003, p. 68). Este autor constata que historicamente, no ensino de línguas estrangeiras, tem havido uma veneração da figura do falante nativo, colocando a cultura e a língua estrangeira como superiores e fazendo com que alguns alunos se sintam "diminuídos em sua auto-estima, passando a experimentar um complexo de inferioridade". Ele acrescenta que alguns ainda se sentem "envergonhados de sua condição linguística".

Por outro lado, os depoimentos anteriores mostram também o "reforço narcísico" de se sentir orgulhoso(a) no caso dos que realizaram uma comunicação bem sucedida em inglês. Nesse caso, segundo Charlot (2000, p. 72), "o sucesso escolar produz um potente efeito de 
segurança e reforço narcísico, enquanto que o fracasso causa grandes estragos na relação consigo mesmo". Weedon (apud NORTON, 2011, p. 319, 320) afirma que é "através da linguagem que uma pessoa negocia um sentido de si [...] e que a pessoa ganha acesso - ou tem o acesso negado - a poderosas redes sociais que lhe dão a oportunidade de falar" 5 .

Além da imagem de si, pudemos depreender a relação de alguns alunos com a linguagem:

Na realidade, eu consegui entender "a idéia geral" do diálogo. Porém, não consegui entender todas as palavras, pois ele falava muito rápido. Eu me senti muito bem, principalmente pelo fato de estar falando com uma pessoa de outro lugar, do Canadá. (Aluno da escola particular, $9^{\circ}$ ano)

Mesmo não entendendo perfeitamente tudo, o aluno conseguiu realizar um diálogo, conforme atestam suas palavras. Para ele, o importante é que nessas interações o sentido pôde ser negociado, resultando na abertura de uma comunicação significativa entre pessoas de culturas e línguas diferentes. Outro aluno relata sua experiência:

Era feriado da mudança da capital em 2006, eu estava indo para a minha casa de praia e minha mãe encontrou uma colega dela. A colega dela disse que estava com uma intercambista de Portland (EUA), então minha mãe me chamou para conversar com ela (a estrangeira), pois ela estava muito sozinha. Foi a primeira vez que conversei em inglês com um estrangeiro. Eu fiquei muito nervoso e errei umas coisas, mas foi ótimo porque eu consigo ser independente apesar de ficar nervoso e errar, mas depois eu mesmo conserto meus erros. (Aluno da escola particular, $9^{\circ}$ ano)

Este relato destaca, entre outras coisas, a relação que o aluno estabelece com a linguagem, construindo-se no discurso como locutor que possui flexibilidade linguística (BAUTIER, 1995). Ele transita entre com versatilidade entre a narrativa e a análise e explicação. Ele também se constrói no discurso como indivíduo capaz de realizar reflexões acerca de sua própria competência linguística e da capacidade de aprender com os próprios erros de maneira autônoma.

Ao comentarem sobre suas interações com estrangeiros, os alunos revelaram as impressões que tiveram desse tipo de experiência. Pode ter sido algo estranho ou motivo de orgulho perceberem-se construindo significados em outra língua, com alguém de outro país.

Conforme ressalta Almeida Filho (2005, p. 12, 15), “essa nova língua pode ser tida em melhor perspectiva como uma língua que também constrói seu aprendiz" e, ao ser "falada com propósitos autênticos", pode também "falar esse mesmo aprendiz, revelando índices de

\footnotetext{
${ }^{5}[\ldots]$ it is through language that a person negotiates a sense of self [...] and it is through language that a person
} gains access to - or is denied access to - powerful social networks that give learners the opportunity to speak. 
sua identidade e das significações próprias dessa língua-alvo". Isso está em conformidade com Rajagopalan (2003, p. 69), quando afirma que "quem aprende uma língua nova está se redefinindo como uma nova pessoa", e com Norton (1997, p. 410), que destaca:

[...] cada vez que os aprendizes de uma língua falam, eles não estão apenas trocando informações com seus interlocutores; eles estão também constantemente organizando e reorganizando um sentido de quem eles são e de que como eles se relacionam com o mundo. Eles estão, em outras palavras, engajados na reconstrução e negociação de identidades. ${ }^{6}$

A realização de uma interação comunicativa bem sucedida com o outro, com alguém de cultura diferente tende a exercer um efeito positivo sobre o conceito que o aprendiz tem de si mesmo, de suas consecuções e de sua própria cultura. Isso pode, inclusive, mobilizá-lo a querer aprender mais sobre o idioma, conforme atestam alguns alunos que já se comunicaram em inglês com estrangeiros:

Eu me senti mais interessada em inglês. (Aluna da escola particular / $6^{\circ}$ ano)

Perguntei o nome dele e ele o meu. Ele já sabia falar um pouco o "brasileiro", assim pedi algumas traduções e começamos até a brincar com nossos idiomas. (Aluno da escola pública / $9^{\circ}$ ano)

Eu me senti muito orgulhosa, porque já estudo inglês há muito tempo, pude utilizá-lo para uma coisa legal. Quero aprender mais e mais. (Aluna da escola particular $/ 6^{\circ}$ ano)

Estes últimos depoimentos mostram como a experiência de colocar em prática seus conhecimentos do idioma pôde contribuir para o seu investimento na aprendizagem, pois, segundo Norton (2011), o investimento está relacionado à busca de uma significativa conexão entre o desejo e o compromisso do estudante em aprender a língua e sua identidade.

Em um desses últimos depoimentos, a aluna manifestava a satisfação de um desejo colocado em prática: seus conhecimentos de inglês. Para Develay (1996, p. 88), os alunos, muitas vezes, podem não se interessar em aprender na escola porque os saberes lhes parecem:

[...] desconectados do seu uso, separados do pensamento, porque não estão vinculados a uma utilização operacional. Aprendemos, eles pensam, por aprender, não necessariamente para pôr em prática ou para analisar uma

\footnotetext{
${ }^{6}[\ldots .$.$] every time language learners speak, they are not only exchanging information with their interlocutors; they$ are also constantly organizing and reorganizing a sense of who they are and how they relate to the social world. They are, in other words, engaged in identity construction and negotiation.
} 
realidade com o que se sabe. $\mathrm{O}$ saber não é nem um operador, nem um analisador. $^{7}$

Quando os alunos veem seus conhecimentos postos em prática, quer seja em uma situação vivida ou em uma situação de análise, eles conseguem implicar-se e investir-se nessa ação e percebem-se como capazes de mobilizar o que aprenderam, de estabelecer relações entre conhecimentos que porventura lhes pareciam fragmentados. Isso contribui para que o aluno dê sentido à aprendizagem.

\section{Considerações finais}

O objetivo deste artigo foi destacar a relevância de se considerar a dimensão identitária no ensino de línguas estrangeiras, especificamente da língua inglesa, não pretendendo fazer apologia ao idioma inglês, mas visto que ele é a língua da globalização, concordo com a afirmação de que devemos dominá-lo e jamais permitir que ele nos domine (RAJAGOPALAN, 2003, p. 70). Entendo que a atenção para as relações entre identidade e o ensino de línguas estrangeiras é de especial importância no mundo globalizado em que as relações com o tempo e o espaço têm se encurtado e em que as identidades estão cada vez mais cambiantes.

Foi verificado, através de alguns resultados de uma pesquisa de mestrado, de que modo as atividades de interações comunicativas autênticas puderam contribuir para a (re)construção de identidades dos alunos, para desenvolver sua autoestima e contribuir para o seu investimento na aprendizagem do idioma. A pergunta sobre a comunicação especificamente com um estrangeiro foi feita assim não pela mitificação do falante nativo, mas porque a pesquisadora não foi neutra. Agora posso ver claramente que aquilo remetia a minha primeira interação comunicativa com estrangeiros: ao pensamento de que negociamos sentidos e de que eles me entenderam "apesar" da minha pronúncia e da minha entonação. Este último pensamento com a palavra "apesar" soa um tanto colonialista, mas a experiência foi libertadora, um "Abre-te, Sésamo", pois não ficaram corrigindo meus "erros" como meu professor fazia.

Os alunos dessa pesquisa revelaram o desejo de que fossem enfatizados, no ensino do inglês, os aspectos comunicativos da língua, pois para eles saber o idioma é saber falar e entender. Seu sucesso na comunicação representou um grande reforçador narcísico, pois se sentiram orgulhosos de poderem entender e se fazerem entendidos por outros. Passaram a se interessar mais pelo idioma e a investir em sua aprendizagem.

No entanto, esse tipo de experiência se deu quase que exclusivamente com alunos de uma escola particular de classe média, e, na maioria das vezes, em contextos de viagem e

\footnotetext{
${ }^{7}$ Le savoir leur apparaît souvent déconnecté de son usage, coupé meme de la pensé, parce que non relié à un usage opérationnel. On apprend pensent-ils pour apprend, pás forcément pour faire ou pour analyser une realité avec ce que l'on sait. Le savoir n'est ni un opérateur, ni un analyseur.
} 
lazer. Da amostra pesquisada, apenas cerca de $40 \%$ dos alunos da escola particular contra $2 \%$ dos da escola pública já utilizaram o inglês para a comunicação com estrangeiros. A diferença nos percentuais é significativa, visto que os alunos da escola particular provavelmente transitam em ambientes mais propícios à realização dessas interações, e é provável que possuam melhor proficiência oral no idioma, pois grande parte deles também estuda em cursos livres. Eles geralmente têm acesso aos lugares em que há maior circulação de pessoas estrangeiras, como em viagens, hotéis, restaurantes etc., pois o intercâmbio cultural, econômico e político ainda não é muito expressivo em Aracaju/SE, no âmbito presencial, pelo menos. Isso chama a atenção para a necessidade de novas posturas e práticas no ensino desse idioma, especialmente agora com a Internet e as novas relações como tempo e o espaço, a fim de que o ensino de língua inglesa seja mais significativo para eles.

\section{Referências}

ALMEIDA FILHO, José Carlos Paes de. Dimensões comunicativas no ensino de línguas. 4. ed. Campinas, SP: Pontes, 2005.

AUGÉ, Marc. Por uma antropologia da mobilidade. Tradução Bruno César Cavalcanti e Rachel Rocha de A. Barros. Maceió: Edufal, UNESP, 2010.

BAUTIER, Elisabeth. Pratiques langagières, pratiques sociales: De la sociolinguistique à la sociologie du langage. Paris: Editions L’Harmattan, 1995.

BERNARDO, Aline Cajé. Relações como o aprender: um estudo sobre a aprendizagem de língua inglesa no ensino fundamental. 2010. 156 f. Dissertação (Mestrado em Educação). Universidade Federal de Sergipe. São Cristóvão, SE, 2010.

CHARLOT, Bernard. Da relação com o saber: elementos para uma teoria. Tradução Bruno Magne. Porto Alegre: Artes Médicas Sul, 2000.

Relação com o saber, formação dos professores e globalização: questões para a educação de hoje. Porto Alegre: Artmed, 2005.

Educação e Globalização. Uma tentativa de colocar ordem no debate. Sísifo Revista de Ciências da Educação, 4, p. 129-136. 2007.

DEVELAY, Michel. Donner du sens à l'école. Paris: ESF editeur, 1996.

HALL, Stuart. A identidade cultural na pós-modernidade. Trad. Tomás Tadeu da Silva e Guacira Lopes Louro. Riode Janeiro: DP\&A Editora, 2005.

KUMARAVADIVELU, B. Cultural realism and pedagogic principles. In: KUMARAVADIVELU, B. Cultural globalization and language education. $1^{\text {st }}$ edition. Yale University Press: 2007.

NORTON, Bonny. Language, Identity, and the Ownership of English. TESOL Quarterly. Vol. 31. No 3, Autumn, 1997. p. 409-429. 
Identity. The Routledge Handbook of Applied Linguistics. Edited by James Simpson. New York and London, 2011. p. 318-330.

RAJAGOPALAN, Kanavillil. Por uma linguística crítica: Linguagem, Identidade e a Questão Ética. São Paulo: Parábola Editorial, 2003.

REVUZ, Christine. A língua estrangeira entre o desejo de um outro lugar e o risco do exílio. Tradução de Silvana Serrani-Infante. In: SIGNORINI, I. (Org.). Língua(gem) e Identidade: elementos para uma discussão no campo aplicado. Campinas, SP: Mercado de Letras; São Paulo: Fapesp, 1998.

SUÁREZ-OROZCO, Carola. Formulating Identity in a Globalized World. In: SUÁREZOROZCO, Marcelo M. \& QIN-HILLIARD, Desiree (Editors). Globalization, Culture \& Education in the New Millenium. University of California Press \& Ross Institute (Preprint forthcoming February, 2003). 